\title{
ANÁLISES ONTOGENÉTICAS EM SEMENTES DE EUPHORBIACEAE
}

\author{
Jonathas Henrique Georg de Oliveira ${ }^{1}$, Adelita Aparecida Sartori Paoli ${ }^{2}$ \\ ${ }^{1}$ Biologico, Dr., Depto. de Biologia, UEM, Maringá, PR, Brasil - jonathas229@yahoo.com.br \\ ${ }^{2}$ Naturalista, Dr ${ }^{\mathrm{a}}$., Depto. de Botânica, UNESP, Rio Claro, SP, Brasil - aapaoli@rc.unesp.br
}

Recebido para publicação: 21/06/2013 - Aceito para publicação: 01/11/2013

\begin{abstract}
Resumo
Acalypha gracilis, Euphorbia cotinifolia e Jatropha gossypiifolia pertencem a Euphorbiaceae e às respectivas subfamílias Acalyphoideae, Euphorbioideae e Crotonoideae. Informações sobre morfologia e desenvolvimento seminal de Euphorbiaceae são escassas na literatura. Este estudo tem por objetivo acompanhar o desenvolvimento morfoanatômico das espécies em questão. Os óvulos dessas espécies são anátropos, sésseis, crassinucelados e bitegumentados. A micrópila, em linha reta, é delimitada pelo endóstoma e exóstoma, é obliterada pela projeção do nucelo, não muito evidente em A. gracilis, que pode alcançar o obturador. As sementes são consideradas exotégmicas, albuminosas, com endosperma na maturidade contendo grãos de aleurona. O embrião apresenta eixo hipocótiloradicular curto e cônico, cotilédones largos e foliáceos, sendo diferenciado tardiamente - primeiro ocorre todo o desenvolvimento do envoltório seminal, para que depois ele se desenvolva por completo. Jatropha gossypiifolia é endopaquicalazal e apresenta endosperma misto: núcleo-celular. Carúncula bem evidente ocorre em J. gossypiifolia, sendo que nas outras duas espécies é inconspícua. Palavras-chave: Anatomia; endosperma; morfologia; nucelo; tegumento.
\end{abstract}

\begin{abstract}
Ontogenetic analyzes in seeds of Euphorbiaceae. Euphorbia cotinifolia and Jatropha gossypiifolia belong to Euphorbiaceae, and to the respective subfamilies Acalyphoideae, Euphorbioideae and Crotonoideae. Information on morphology and seminal development of Euphorbiaceae are lean in literature. This research aims to monitor the morphoanatomic development of the involved species. The ovule of these species are anatropous, sessile, bitegmic and crassinucelate. The micropyle, straight, is bounded by endostome and exostome, and obliterated by the projection of the nucellus, not very evident in A. gracilis. The seeds are considered exotégmic, albuminous endosperm at maturity containing aleurone grains. The embryo with hypocotyl-radicle axis is short, broad and foliaceous cotyledons, being distinguished later: first, all the seminal wrap development occurs, so that it evolves completely. $J$. gossypiifolia is endopachichalazal and presents mixed endosperm: cell nucleous. Caruncule is evident in J. gossypiifolia, but it is inconspicuous in the other two species.

Keywords: Anatomy; endosperm; morphology; nucellus; integument.
\end{abstract}

\section{INTRODUÇÃO}

Euphorbiaceae é uma família muito diversificada, apresentando espécies com hábitos variados, tais como ervas, árvores ou arbustos, lianas e até mesmo afilas, sendo comum a ocorrência de indivíduos com inflorescências cimosas ou racemosas, formando um ciátio (SOUZA; LORENZI, 2008). De acordo com esses mesmos autores, distribuem-se de maneira ampla por todo o globo, abrangendo aproximadamente 300 gêneros e 6.000 espécies. Já Judd et al. (2009) relataram 222 gêneros e 6.100 espécies. No Brasil, são encontrados cerca de 70 gêneros e 1.000 espécies, sendo uma das famílias mais representativas da flora brasileira e complexa do ponto de vista taxonômico (SOUZA; LORENZI, 2008).

Suas sementes são, em geral, exotégmicas, albuminosas, exariladas, com ou sem carúncula, com tegumentos multiplicativos ou não. Apresenta testa, geralmente, de paredes finas e o exotégmen como camada mecânica. Em vários gêneros da subfamília Crotonoideae, encontra-se uma paquicalaza (CORNER, 1976). 
Em 1994, Webster apresentou cinco subfamílias para Euphorbiaceae: Phyllanthoideae e Oldfieldioideae (com dois óvulos por lóculo) e Acalyphoideae, Crotonoideae e Euphorbioideae (com um óvulo por lóculo). Angiosperm Philogeny Group (APG, 2003) reorganizou-as em três subfamílias apenas, sendo as que apresentam apenas um óvulo por lóculo, enquanto que as outras duas, Phyllanthoideae e Oldfieldioideae passaram a integrar, respectivamente, as famílias Phyllanthaceae e Picrodendraceae.

Euphorbiaceae não tem despertado muito interesse dos poucos pesquisadores que trabalham com a linha reprodutiva das plantas, motivo pelo qual encontram-se poucos trabalhos na área, com destaque para Landes (1946), em estudo sobre as sementes de Acalypha rhomboidea Raf.; Singh (1954, 1969), com análise do desenvolvimento de sementes de Ricinus communis L. e Euphorbia helioscopia Hausskn. ex. DC., respectivamente; Berg (1975), que promoveu análise de frutos, sementes e mirmecocoria em espécies de Micrantheum; Corner (1976), com grande obra sobre as sementes de dicotiledôneas; Paoli et al. (1995), que promoveram análise de caracteres morfológicos de frutos, sementes e plântulas de Croton floribundus Spreng. e C. urucurana Baill.; Tokuoka e Tobe (1998, 2002, 2003), em estudos sobre óvulos e sementes nas subfamílias Crotonoideae, Euphorbioideae e Acalyphoideae, respectivamente; Mendivelso et al. (2003), com análise da estrutura morfológica e anatômica de Euphorbia peplus L.; Oliveira e Oliveira (2009), em estudo sobre a morfoanatomia do pericarpo de Manihot caerulescens Pohl. e $M$. tripartita Müll. Arg.; Demarco e Carmello-Guerreiro (2011), com contribuição sobre a ontogenia do pericarpo e a histoquímica da testa e da pseudocarúncula de Euphorbia milii Des Moul.; e, para finalizar, Gagliardi et al. (2012), com análise da estrutura e desenvolvimento de frutos e sementes de espécies invasoras de Euphorbiaceae.

Certas características são de fundamental importância no entendimento da família, como a presença do obturador e de projeção do nucelo, assim como a presença da carúncula nas sementes (KAPIL; BHATNAGAR, 1994).

Sabe-se que óvulos e sementes, em geral, exibem grande riqueza de características que devem ser consideradas na classificação das plantas (VON TEICHMAN; VAN WYK, 1991). Essas autoras mencionaram que a procura por informações sobre frutos e sementes, a fim de complementar aquelas provenientes de órgãos vegetativos, é cada vez maior, para que possam ser evitadas as interpretações equivocadas que análises baseadas somente na morfologia desses órgãos podem causar. Afirmaram, ainda, que análises de órgãos reprodutivos são relevantes, que devem ser levadas em conta na classificação das plantas, principalmente por esses órgãos sofrerem menos influências ambientais, e que a falta de evidências ontogenéticas e descritivas dessas estruturas promove dificuldades para a especulação sobre pontos evolutivos que possam interferir nos processos de classificação.

Assim, os objetivos deste estudo foram descrever a morfologia e anatomia das sementes de Acalypha gracilis Spreng., Euphorbia cotinifolia L. e Jatropha gossypiifolia L. em diversas fases do desenvolvimento, e identificar e relacionar as estruturas que as compõem, verificando possíveis padrões estruturais comuns às diferentes espécies.

\section{MATERIAL E MÉTODOS}

Flores e frutos em diferentes estágios de desenvolvimento foram coletados de diferentes indivíduos, em Maringá, PR. A. gracilis foi coletada no Bosque dos Pioneiros, sob as coordenadas $23^{\circ} 26^{\prime} 11,93$ ” S; 51 56'27,94” S; E. cotinifolia foi coletada na Rua das Azaleias, próximo ao Horto Florestal $\left(23^{\circ} 26^{\prime} 24,13^{\prime \prime}\right.$ S; $51^{\circ} 57^{\prime} 48,36^{\prime \prime}$ O); e $J$. gossypiifolia foi encontrada próxima à divisa com o município de Sarandi $\left(23^{\circ} 25^{\prime} 01,02^{\prime}\right.$ S; $51^{\circ} 55^{\prime} 14,79^{\prime}$ O). Os ramos férteis foram depositados no Herbário da Universidade Estadual de Maringá (HUEM), sob os seguintes registros: A. gracilis: 20937, E. cotinifolia: 20936 e J. gossypiifolia: 20938.

Os óvulos e as sementes foram fixados, desidratados, incluídos em metacrilado Leica ${ }^{\circledR}$ (de acordo com instruções do fabricante) e corados seguindo os protocolos de morfoanatomia vegetal estabelecidos por Johansen (1940), Jensen (1962) e O’Brien et al. (1964). O meio de montagem foi Entellan ${ }^{\circledR}$.

Foram realizados os seguintes testes histoquímicos: floroglucinol com adição de ácido clorídrico concentrado, para evidenciar paredes lignificadas (SASS, 1951); Sudan IV, para a localização de substâncias lipídicas; e Lugol, para a detecção de amido e cloreto férrico, a fim de se verificar a ocorrência de compostos fenólicos (JOHANSEN, 1940). Ácido pícrico com adição de solução de eosina $1 \%$,foi usado para evidenciar reservas proteicas sob a forma de grãos de aleurona (OLIVEIRA; SAITO, 
2000). Para a descrição dos resultados, utilizou-se a terminologia proposta por Martin (1946), Corner (1976) e Werker (1997).

O laminário confeccionado foi analisado com auxílio de estereoscópio EZ4D Leica e microscópio óptico Olympus BX 50. Os resultados foram documentados com fotografias tiradas com câmera Canon Power A95. O tamanho das sementes foi mensurado com uso de paquímetro.

\section{RESULTADOS}

Estrutura do óvulo - nas três espécies, os óvulos sésseis são únicos em cada lóculo, anátropos, com placentação axial e micrópila voltada para o ápice do ovário. J. gossypiifolia o apresenta sob forma elíptica, enquanto que nas outras duas espécies tem formato ovalado (Figuras 1-3). O obturador fica em contato com a projeção do nucelo (Figuras 2-3); sendo pouco desenvolvida em A. gracilis, formada por poucas camadas celulares e de difícil observação. O obturador de $J$. gossypiifolia é formado por células parenquimáticas, cuboides com compostos fenólicos, em A. gracilis e em E. cotinifolia e com núcleos bem evidentes, que se alongam em direção à projeção do nucelo (Figuras 2-4).

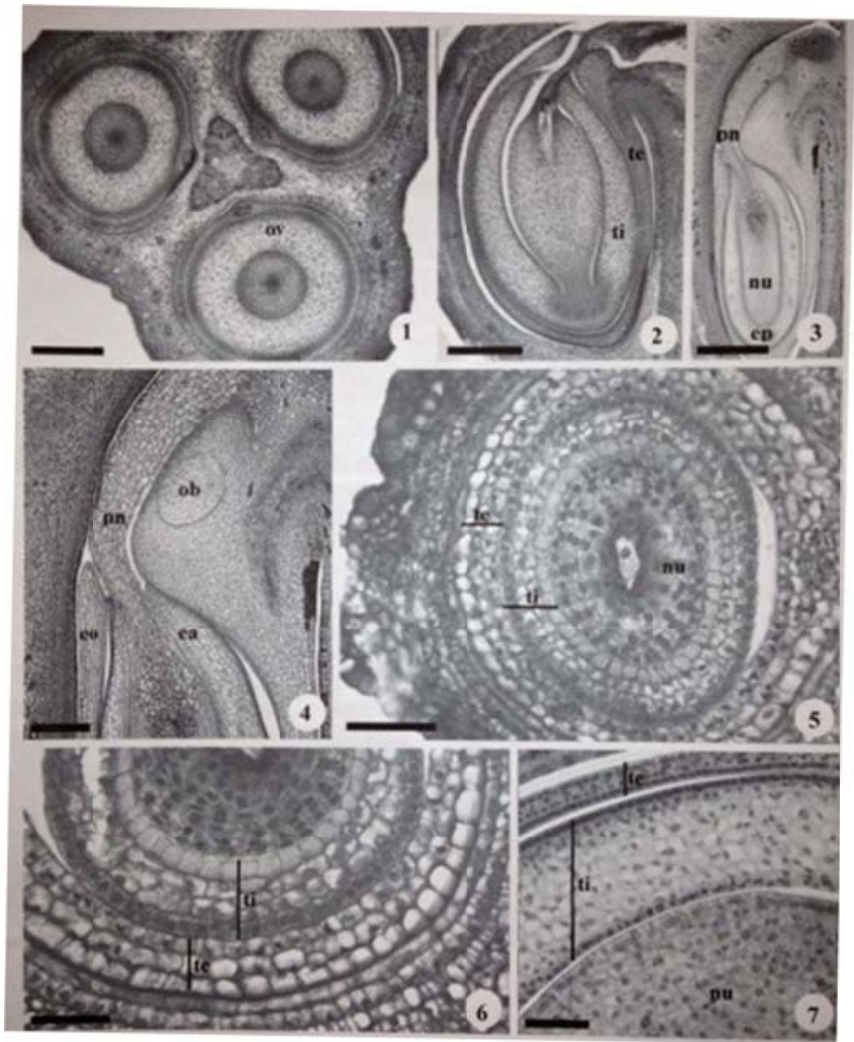

Figuras 1-7. Estrutura do óvulo de Acalypha gracilis (5-6), Euphorbia cotinifolia (1-2, 7) e Jatropha gossypiifolia (3-4). Seções longitudinais (2-4). Seções transversais (1, 5-7). 1. Vista geral do ovário trilocular ocupado por três óvulos; 2-3. Vista geral de óvulo anátropo, acompanhado de obturador e inserido em placentação axial; 4. Vista da micrópila com projeção do nucelo; 5 . Vista geral dos tegumentos e nucelo; 6-7. Pormenores dos tegumentos interno e externo. (ea = endóstoma; el = endotélio; eo = exóstoma; ep = endopaquicalaza; nu = nucelo; ob = obturador; ov = óvulo; $\mathrm{pn}=$ projeção do nucelo; te = tegumento externo; $\mathrm{ti}=$ tegumento interno). Barras $=500$ $\mu \mathrm{m}$ (3), $200 \mu \mathrm{m}$ (1-2), $150 \mu \mathrm{m}$ (4), $50 \mu \mathrm{m}$ (5, 7), $35 \mu \mathrm{m}$ (6).

Figures 1-7. Structure of the ovule Acalypha gracilis (5-6), Euphorbia cotinifolia (1-2, 7) and Jatropha gossypiifolia (3-4). Longitudinal sections (2-4). Cross sections (1, 5-7). 1. Overview ovarian trilocular occupied by three ovules; 2-3. Overview of ovule anatropous, accompanied by shutter and inserted axial placentation; 4. View the micropyle nucellus with projection; 5. Overview of integuments and nucellus; 6-7. Details of the inner and outer integuments. (ea = endostome; el = 
endothelium; eo = exostome; ep = endopaquicalaza; nu = nucellus; ob = obturator; ov = ovule; pn $=$ nucellus projection; te $=$ outer integument; $\mathrm{ti}=$ inner integument). Bars $=500$ micrometer (3), 200 micrometer (1-2), $150 \mu \mathrm{m}$ (4), $50 \mu \mathrm{m}$ (5, 7), $35 \mu \mathrm{m}(6)$.

Os óvulos são crassinucelados e bitegumentados. A. gracilis mostra três estratos celulares no tegumento externo e quatro no interno (Figuras 5-6), E. cotinifolia tem cerca de 4-5 estratos no externo e até 11 no interno (Figura 7) e J. gossypiifolia apresenta, aproximadamente, cinco estratos no tegumento externo e 16 no interno. A micrópila nas três espécies está disposta praticamente em linha reta, delimitada pelo exóstoma e endóstoma, ao redor da projeção do nucelo (Figuras 2-4).

Os tegumentos são cuticularizados, sendo que a cutícula é mais evidente na epiderme externa do tegumento externo. Em E. cotinifolia, a epiderme que compõe as duas faces do tegumento interno é composta por células um pouco mais densas que as demais (Figura 7); em A. gracilis, as células das epidermes externa e interna do tegumento interno apresentam leve diferença. A primeira é mais densa, com núcleos grandes e centrais e leve alongamento radial; a segunda é formada por células grandes ricas em compostos fenólicos, sendo uma região de grande destaque (Figuras 5-6), perfazendo o endotélio, tecido não relatado anteriormente em Euphorbiaceae.

O nucelo parenquimático é formado por células cuboides, com grandes núcleos e amplos vacúolos, com exceção de $A$. gracilis, onde as células não têm forma única e típica. Esse tecido é circundado por epiderme uniestratificada e cuticularizada. As células que se projetam além dos tegumentos são semelhantes às demais, porém menores (Figuras 5-7).

Euphorbia cotinifolia e A. gracilis mostram óvulos vascularizados por um único feixe vascular colateral, que atravessa toda a rafe no tegumento externo, penetra na calaza e não se ramifica (Figura 2). Em $J$. gossypiifolia, o feixe colateral que percorre todo o tegumento externo, ao penetrar na calaza se ramifica intensamente no tegumento interno, originando a endopaquicalaza, ficando o tegumento interno restrito à região micropilar (Figura 3). A endopaquicalaza, amplamente vascularizada, forma uma estrutura anelar com aproximadamente 25 feixes vasculares ao redor do nucelo (Figura 9).

Semente em desenvolvimento - As sementes de J. gossypiifolia apresentam carúncula bem diferenciada, originada de intensas divisões celulares do ápice do tegumento externo, nas proximidades do exóstoma. Nas outras duas espécies, também ocorre carúncula, formando uma leve protuberância ao redor da micrópila, porém não tão desenvolvidas e proeminentes quanto a de J. gossypiifolia.

Nas três espécies, o tegumento externo passa a constituir a testa, formada pela exo, meso e endotesta, enquanto que o tegumento interno forma o tégmen, este formado pelo exo, meso e endotégmen. J. gossypiifolia apresenta tegumentos multiplicativos (Figuras 11, 14), em função de divisões periclinais, enquanto que em $A$. gracilis e em E. cotinifolia os tegumentos não são multiplicativos (Figuras 10, 12, 13). Os estratos da testa, nesse estágio, praticamente não sofrem alteração em nenhuma das espécies analisadas; apenas as células da exotesta de $J$. gossypiifolia apresentam divisões anticlinais e leve alongamento, com raros estômatos (Figura 11), e a endotesta aumenta levemente seu volume (Figuras 8, 13).

O tégmen sofre mais alterações quando comparado com a testa. As células do exotégmen aumentam de volume, sofrem espessamento parietal, alongamento anticlinal (iniciando, principalmente, na região micropilar e calazal) e, ao final, passam por uma leve curvatura, mostrando-se parcialmente oblíquas (Figuras $8,10,11,14)$. No mesotégmen de $J$. gossypiifolia ocorre um intenso desenvolvimento, devido às inúmeras divisões e alongamentos celulares. As células mesotégmicas localizadas nas proximidades do endotégmen continuam o processo de divisão celular, e, mesmo aumentando de volume, se mantêm como as menores desse tecido (Figuras 11, 14). As células do endotégmen sofrem um leve alongamento anticlinal e espessamento parietal em E. cotinifolia e J. gossypiifolia (Figura 14). Em A. gracilis, as células do endotégmen mostram-se mais alongadas periclinalmente, com paredes espessadas e uma grande quantidade de compostos fenólicos. Esse tecido, à medida que passa o desenvolvimento seminal, vai sendo comprimido (Figuras 8, 15).

O endosperma é nuclear nas três espécies, por grande período de tempo. Ao final do processo de desenvolvimento, os núcleos livres iniciam um processo de celularização, originando células cuboides com grandes núcleos centrais, com um ou dois nucléolos bem evidentes (Figuras 15, 16, 17). O embrião, pequeno, está em início de desenvolvimento.

As células do nucelo aumentam bastante de volume nas três espécies, inclusive as da epiderme. $\mathrm{O}$ nucelo apresenta uma projeção que se estende entre os tegumentos e chega até o obturador, sendo mais acentuada em J. gossypiifolia, onde permite a visualização inclusive de muitos grãos de amido. Essa projeção vai sendo consumida, restando apenas resíduos de origem péctica nas proximidades da micrópila. Todo o nucelo vai sendo consumido centrifugamente (Figura 17). 
Uma hipóstase de células com espessamento parietal e com acúmulo de substâncias fenólicas é evidente na região calazal (Figuras 17, 18), com exceção de E. cotinifolia.

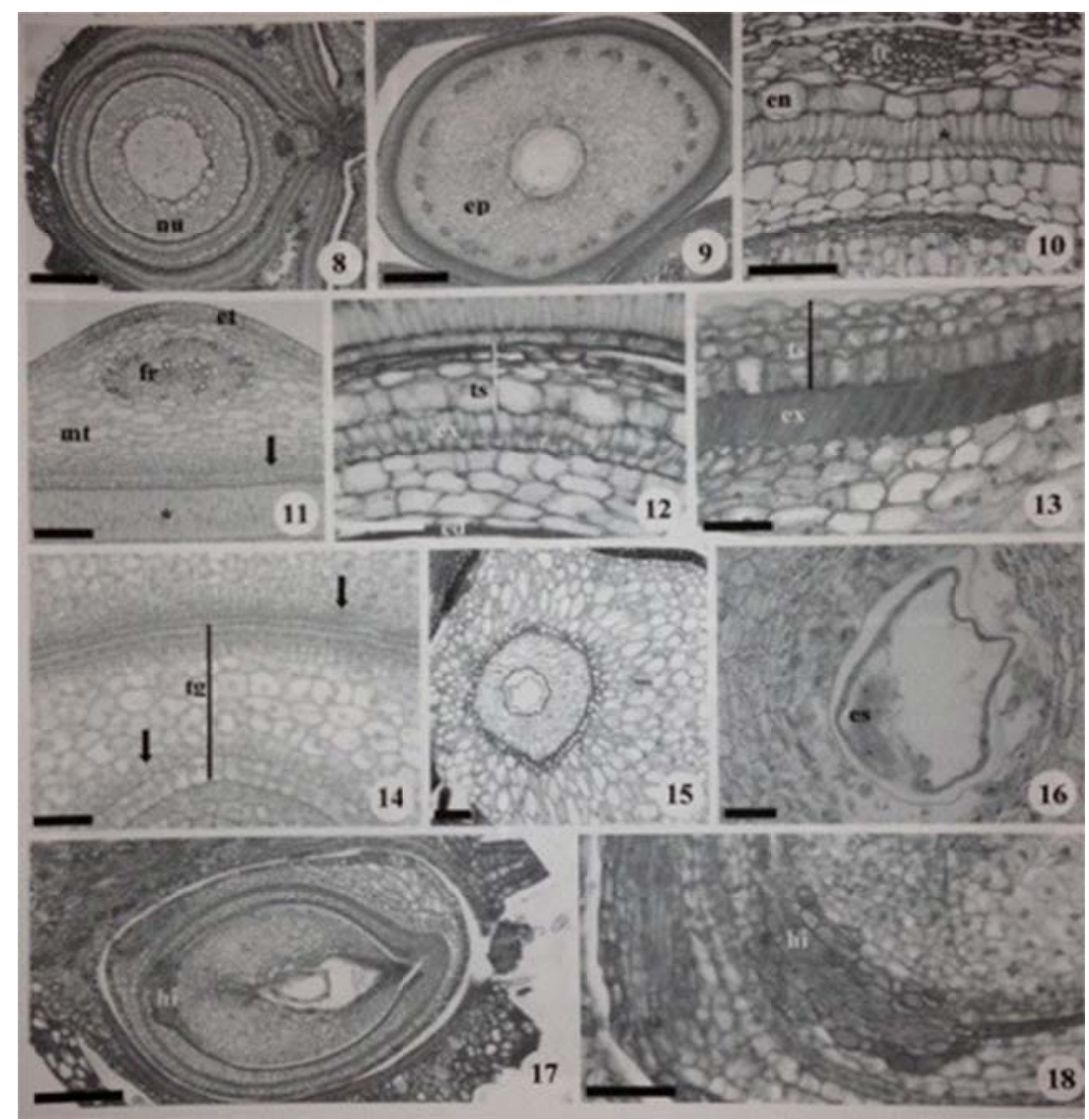

Figuras 8-18. Desenvolvimento da semente de Acalypha gracilis (8, 10, 12, 17-18), Euphorbia cotinifolia $(13,15)$ e Jatropha gossypiifolia $(9,11,14,16)$. Seções longitudinais $(13,18)$. Seções transversais (8-12, 14-17). 8-9. Visão geral das sementes em desenvolvimento; 10-11. Detalhe da rafe, destacando o feixe rafeal (notar divisões periclinais internas na mesotesta seta, e alongamento das células exotégmicas - asterisco); 12-13. Detalhes da testa e exotégmen em alongamento; 14. Pormenor do tegumento interno e porção mais interna do tegumento externo, com divisões periclinais (seta); 15. Visão geral do endosperma nuclear; 16. Detalhe de endosperma nuclear; 17. Aspecto geral da semente (notar, na região calazal, presença de hipóstase); 18. Detalhe da hipóstase da figura anterior. (ed = endotégmen; em = endotesta; ep = endopaquicalaza; es = endosperma; et = exotesta; ex = exotégmen; $\mathrm{fr}=$ feixe rafeal; hi = hipóstase; $\mathrm{mt}=$ mesotesta; $\mathrm{nu}=$ nucelo; tg = tégmen; ts = testa). Barras = $200 \mu \mathrm{m}$ (8-9), $150 \mu \mathrm{m}$ (17), $100 \mu \mathrm{m}(10-11,15), 50 \mu \mathrm{m}(12-14,16,18)$.

Figures 8-18. Development seeds of Acalypha gracilis (8, 10, 12, 17-18), Euphorbia cotinifolia (13, 15) and Jatropha gossypiifolia $(9,11,14,16)$. Longitudinal sections $(13,18)$. Cross sections $(8-$ 12, 14-17). 8-9. Overview of the developing seed. 10-11. Detail raphe, highlighting the rafeal bundle (notice the inner periclinal divisions in mesotesta - arrow, and cell elongation exotégmicas - asterisk); 12-13. Details on the forehead and exotegmen stretching; 14. Detail of the inner integument and inner portion of the outer integument, with periclinal divisions (arrow); 15. Overview of nuclear endosperm; 16. Detail of nuclear endosperm; 17. General appearance of the seed, note in the chalazal region, the presence of hypostasis; 18. Detail of the hypostasis of the previous figure. (ed = endotegmen; en = endotesta; ep = endopaquicalaza; es = endosperm; et = exotesta; ex = exotegmen; $\mathrm{fr}$ = rafeal bundle; 
hi $=$ hypostasis; $\mathrm{mt}=$ mesotesta; $\mathrm{nu}=$ nucellus; $\operatorname{tg}=$ tegmen; $\mathrm{ts}=$ testa $)$. Bars $=200 \mu \mathrm{m}(8-$ 9), $150 \mu \mathrm{m}$ (17), $100 \mu \mathrm{m}$ (10-11, 15), $50 \mu \mathrm{m}(12-14,16,18)$.

Semente em maturação - o tegumento das sementes maduras nas três espécies apresenta coloração marrom, embora, em J. gossypiifolia, observem-se algumas manchas escurecidas. A testa é lisa, rafe bem demarcada ao longo do tegumento, hilo levemente pronunciado e micrópila imperceptível.

As sementes maduras de $A$. gracilis apresentam aproximadamente $2 \mathrm{~mm}$ de comprimento por 1,5 mm de largura, forma ovalada, assim como as de E. cotinifolia, que medem, aproximadamente, $3 \mathrm{~mm}$ de comprimento por 2,4 mm de largura. As de $J$. gossypiifolia aparentam formato elipsoide, com as respectivas medidas (comprimento x largura x espessura): 0,8 cm, 0,5 cm e 0,4 cm (Figuras 19, 20, 21).

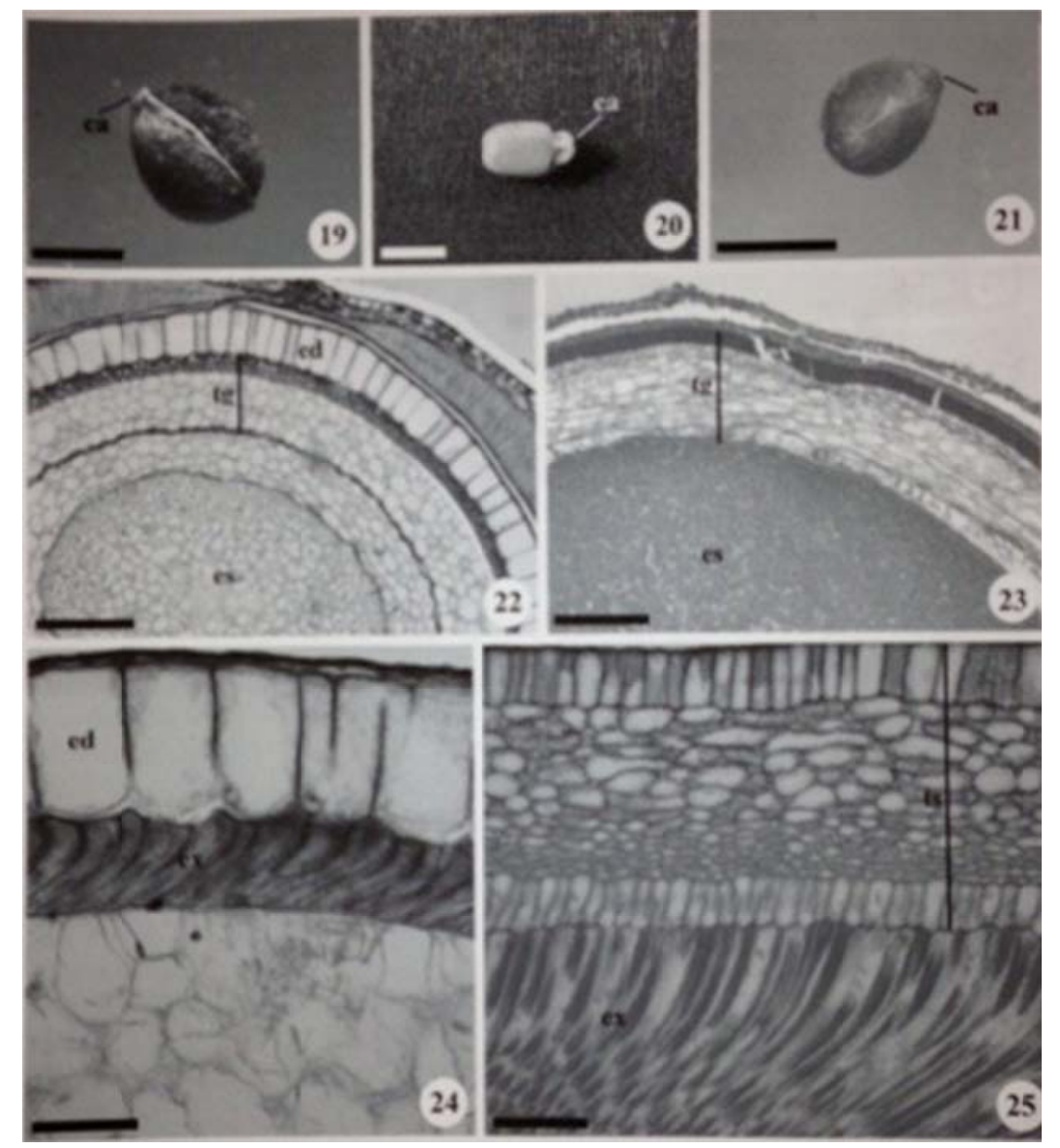

Figuras 19-25. Sementes de Acalypha gracilis (21-22, 24), Euphorbia cotinifolia (19, 23) e Jatropha gossypiifolia (20, 25). Seções longitudinais (25). Seções transversais (22-24). 19-21. Aspecto geral; 22-23. Visão geral dos envoltórios durante o processı de maturação seminal; 24-25. Detalhes dos envoltórios seminais. (ca = carúncula; ed = endotesta; es = endosperma; ex = exotégmen; nu = nucelo; tg = tégmen; ts = testa). Barras $=5 \mathrm{~mm}$ (20), 2 mm (21), 1 mm (19), $200 \mu \mathrm{m}$ (22-23), $100 \mu \mathrm{m}$ (25), $50 \mu \mathrm{m}$ (24).

Figures 19-25. Seeds of Acalypha gracilis (21-22, 24), Euphorbia cotinifolia (19, 23) and Jatropha gossypiifolia (20, 25). Longitudinal sections (25). Cross sections (22-24). 19-21. General appearance; 22-23. Overview of seed coat during the maturation process seminal; 24-25. Details of seed coat. (ca = caruncle; ed = endotesta; es = endosperm; ex = exotegmen; $\mathrm{nu}=$ nucellus; $\mathrm{tg}=$ tegmen; ts = testa). Bars = $5 \mathrm{~mm}$ (20), $2 \mathrm{~mm}$ (21), $1 \mathrm{~mm}$ (19), $200 \mu \mathrm{m}$ (22-23), $100 \mu \mathrm{m}$ (25), $50 \mu \mathrm{m}$ (24). 
A maior parte do envoltório das sementes maduras é formado, em A. gracilis e E. cotinifolia, praticamente pelo tégmen, com destaque para o exotégmen (Figuras 22, 23). Em J. gossypiifolia, o envoltório seminal também é praticamente composto apenas pelo exotégmen, porém tem uma grande participação da endopaquicalaza no tamanho como um todo da semente, pois ela se desenvolve acentuadamente, além de células testais. Principalmente em A. gracilis e E. cotinifolia, podem-se observar resíduos da testa se descamando da semente madura (Figuras 22, 23, 24, 25). Em A. gracilis e E. cotinifolia, as células que compõem a exo e a mesotesta praticamente desaparecem, mostrando-se achatadas e sendo descamadas da estrutura, na sequência (Figuras 23, 24). Em J. gossypiifolia, a exotesta sofre certo espessamento parietal, e na mesotesta há o surgimento de espaços intercelulares, sendo que as células mais internas apresentam leve alongamento tangencial (Figura 25). As células da endotesta em A. gracilis apresentam-se com tamanho bem maior que todas as outras células, sendo vacuoladas e com leve espessamento parietal (Figuras 22, 24). Em $E$. cotinifolia, as células que compõem a endotesta mostram-se suavemente maiores que as demais células testais (Figura 23), e em J. gossypiifolia ocorre alongamento anticlinal nítido na endotesta, a qual se apresenta com células vacuoladas, de paredes delgadas e núcleos centrais (Figura 25).

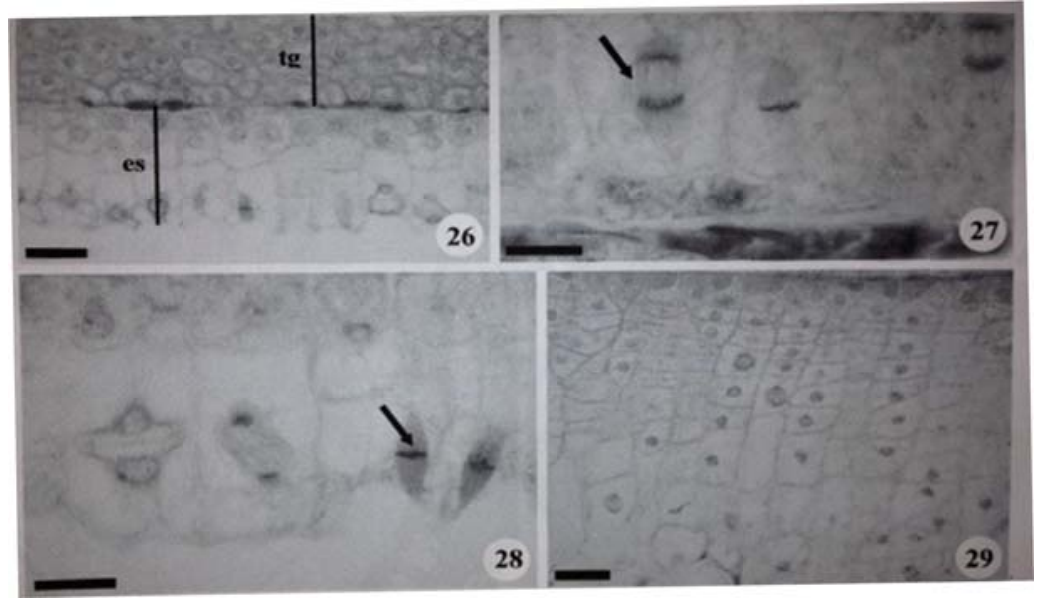

Figuras 26-29. Desenvolvimento do endosperma núcleo-celular de Jatropha gossypiifolia. Seções longitudinais (26-27, 29). Seção transversal (28). 26. Porção interna do tégmen e início de celularização do endosperma; 27-28. Endosperma multisseriado, mostrando divisões celulares mitóticas; 29. Endosperma multisseriado com divisões celulares em linha, modo centrípeto. (es = endosperma; tg = tégmen). Barras $=50 \mu \mathrm{m}(26-29)$, $20 \mu \mathrm{m}(27-28)$.

Figures 26-29. Endosperm development nucleous-cellular of Jatropha gossypiifolia. Longitudinal sections (26-27, 29). Cross section (28). 26. Tegmen inner portion and early cellularization of the endosperm; 27-28. Endosperm multisseriate showing mitotic cell divisions; 29. Endosperm multisseriate with cell divisions in line, inwards. (es = endosperm; tg = tegmen). Bars $=50 \mu \mathrm{m}$ (26-29), $20 \mu \mathrm{m}(27-28)$.

Em J. gossypiifolia, ao redor da micrópila, existe uma carúncula (Figura 20) que contorna o hilo, com pequenas reentrâncias, podendo alcançar aproximadamente $20 \%$ do comprimento da semente. Essa estrutura possui epiderme com células alongadas anticlinalmente e cuticularizadas, contornando um parênquima. Observam-se idioblastos fenólicos e drusas espalhadas (Figura 30).

Em A. gracilis e E. cotinifolia, as células que compõem o mesotégmen são grandes, vacuoladas e sem espaços intercelulares evidentes (Figuras 31, 32, 33). Na segunda espécie, essas células não apresentam uma forma muito típica, estando relativamente comprimidas. Em J. gossypiifolia, as células da porção mais interna do mesotégmen mostram-se achatadas, com alguns cristais e reserva amilífera (Figura 34). Após, praticamente, toda a diferenciação seminal, o embrião inicia seu desenvolvimento, pois até esse momento é inconspícuo.

O endotégmen mostra-se comprimido nas três espécies, contudo, em A. gracilis, essa camada de célula mostra-se com grande quantidade de compostos fenólicos. Vai ocorrendo, também, a reabsorção do nucelo, enquanto o endosperma se prolifera (Figura 31). 
O endosperma e o embrião se desenvolvem e as células componentes do endosperma são cuboides, com núcleos volumosos e centrais, nas três espécies (Figuras 31, 32). No endosperma de $J$. gossypiifolia ocorrem cerca de duas camadas de células de paredes delgadas, originaidas a partir dos núcleos livres. A partir dessas camadas celulares, iniciam-se intensas divisões periclinais (Figuras 26, 27, 28, 29), originando séries de células radiais (Figura 29), mostrando um endosperma com formação mista, pois inicia-se nuclear e depois se celulariza, denominado de núcleo-celular. Em E. cotinifolia e J. gossypiifolia, essas células mostram grande quantidade de reserva para o embrião, a qual se dá por acúmulo de grãos de aleurona, portanto, de origem proteica (Figura 35).

Quando madura, a maior porção das sementes é representada pelo endosperma, o embrião que apresenta cotilédones foliáceos, planos e delgados, o eixo hipocótilo-radicular é curto e cônico; plúmula diferenciada (Figuras 31, 32, 33, 34).

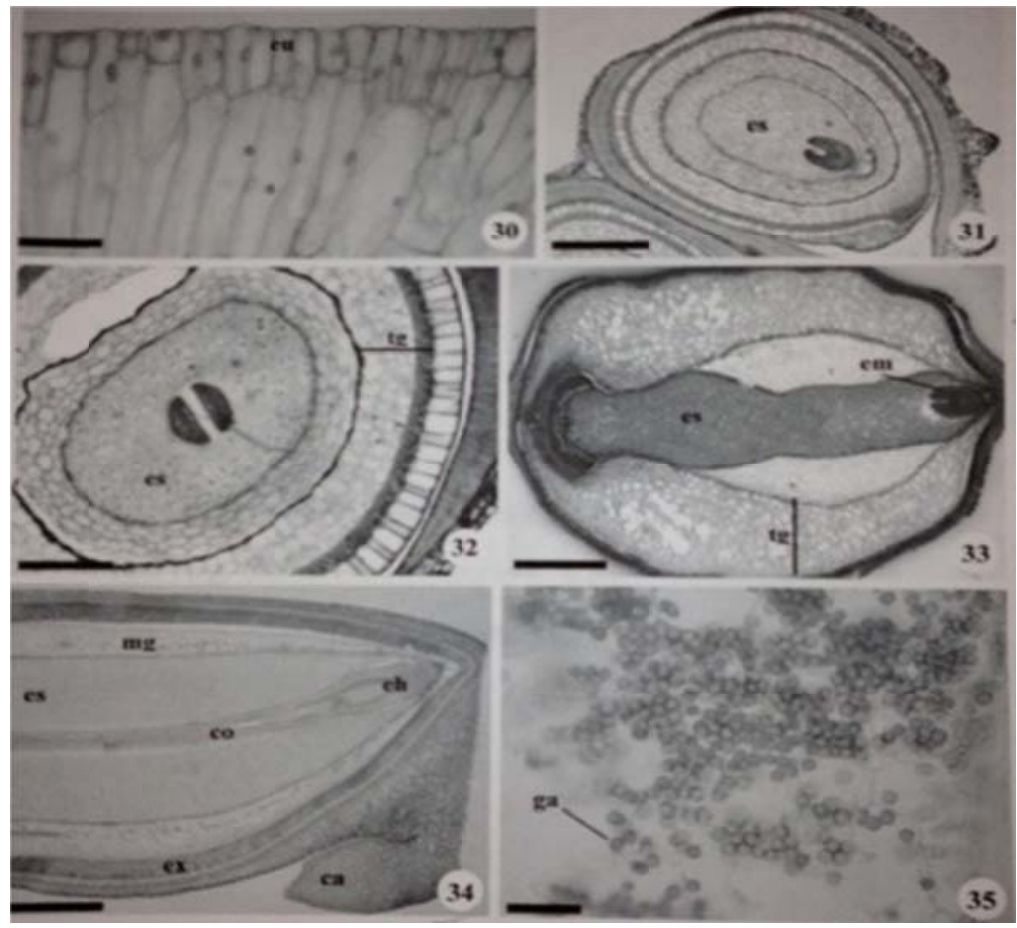

Figuras 30-35. Sementes de Acalypha gracilis (31-32), Euphorbia cotinifolia (33) e Jatropha gossypiifolia (30, 34-35). Seções longitudinais (31, 33-34). Seções transversais (30, 32). 30. Detalhe da carúncula, exibindo epiderme diferenciada; 31-33. Vista geral do embrião em início de diferenciação; 34. Aspecto geral, evidenciando amplo endosperma e embrião com eixo hipocótilo-radícula e cotilédones diferenciados. 35. Detalhe do endosperma, destacando reserva sob a forma de grãos de aleurona. (co = cotilédlone; eh = eixo hipocótilo-radícula; em = embrião; es = endosperma; eu = epiderme da carúncula; ex = exotégmen; $\mathrm{mg}=$ mesotégmen; $\operatorname{tg}=$ tégmen). Barras = 2 mm (34), $200 \mu \mathrm{m}$ (31-33), $50 \mu \mathrm{m}(30,35)$.

Figures 30-35. Seeds of Acalypha gracilis (31-32), Euphorbia cotinifolia (33) and Jatropha gossypiifolia (30, 34-35). Longitudinal sections (31, 33-34). Cross sections (30, 32). 30. Detail of wattle, displaying differentiated epidermis; 31-33. Overview of early embryo differentiation. 34. General appearance, showing large endosperm and embryo hypocotylradicle and cotyledons differentiated; 35. Detail of the endosperm, highlighting reserves in the form of aleurone grains. (co = cotyledon; eh = axis hypocotyl-radicle; em = embryo; es = endosperm; eu = caruncle epiderm; ex = exotegmen; $\mathrm{mg}=$ mesotegmen; $\operatorname{tg}=$ tegmen). Bars = 2 mm (34), $200 \mu \mathrm{m}$ (31-33), $50 \mu \mathrm{m}$ (30, 35). 


\section{DISCUSSÃO}

As sementes de Euphorbiaceae apresentam padrão estrutural bem homogêneo e característico, mesmo com toda a diversidade da família. As observações realizadas no presente trabalho corroboram dados de vários autores, como Corner (1976), Cordeiro (1992), Webster (1994) e Barroso et al. (1999), que descreveram óvulos de Euphorbiaceae como anátropos, bitegumentados, crassinucelados, com presença de obturador, semente com carúncula e rafe bem demarcada.

Revisões de embriologia de Euphorbiaceae revelaram existir mais de 50 caracteres embriológicos de óvulos e sementes, porém são utilizados cinco, mais comuns para comparação entre e até mesmo dentro das subfamílias, como: tegumento interno delgado ou espesso, presença ou ausência de feixes vasculares no tegumento interno; óvulos e sementes paquicalazais ou não; sementes ariladas ou não; exotégmen fibroso ou não (TOKUOKA; TOBE, 2002; 2003). Apesar dos cinco caracteres selecionados, outros autores citaram caracteres também importantes, como Graner (1935), Toledo (1963) e Singh (1969), que relataram presença de obturador, que pode se desenvolver e crescer em direção à micrópila, penetrando-a. Singh (1969) afirmou que o obturador, derivado da placenta, é bem grande e suas células vão em direção à micrópila, assim como Berg (1975), em análises sobre espécies de Micranteum, observou projeções do obturador em forma de tricomas, que preenchem o ápice do lóculo, sendo que, às vezes, podem penetrar na micrópila. As três espécies aqui estudadas mostraram obturador não muito desenvolvido e que não emite nenhum tipo de projeção em direção à micrópila.

Outra característica relevante encontrada em Euphorbiaceae é a projeção do nucelo, que se estende para fora da micrópila (LANDES, 1946; KAPIL; BHATNAGAR, 1994). Estes últimos autores mostraram que essa projeção ocorre em vários gêneros de todas as subfamílias de Euphorbiaceae, e tanto obturador quanto a projeção do nucelo podem estar envolvidos na nutrição do tubo polínico, ou com a função de guia até o saco embrionário. Há de se considerar essa hipótese de nutrição, uma vez que foi encontrada reserva amilácea em várias espécies de Euphorbiaceae, também relatado por Rao e Rao (1976) e Oliveira e Oliveira (2007).

A projeção do nucelo observada em A. gracilis, E. cotinifolia e $J$. gossypiifolia corrobora os dados supracitados. A reserva amilácea foi encontrada, de forma consistente, em J. gossypiifolia. Landes (1946) descreveu também a presença de projeção do nucelo em Acalypha rhomboidea.

Em estudo sobre a embriologia de membros de Euphorbiaceae, Kapil e Bhatnagar (1994) relataram que a projeção do nucelo é inversamente proporcional ao tamanho do obturador, pois quando a projeção do nucelo é reduzida, o obturador é evidente, e quando o obturador é reduzido, a projeção se mostra evidente. Em sementes de Ricinus communis, Singh (1954) mostrou que o ápice do nucelo apresenta forma de cone, sendo que não se estende além da base do endóstoma, não existindo, portanto, a projeção do nucelo através da micrópila.

O material estudado mostra que seus óvulos são formados por células pouco diferenciadas, de paredes delgadas, sem muitos espaços intercelulares, com núcleos evidentes e sem impregnação de lignina. Porém, à medida que os óvulos se desenvolvem em sementes, estas mostram-se exotégmicas, visto que essa camada celular se diferencia abruptamente em relação às demais células, apresentando paredes bem espessadas e com impregnação de lignina, assim como mostram Singh (1969), Corner (1976), Tokuoka e Tobe (1998, 2002 e 2003), Oliveira e Oliveira (2007), Silva e Souza (2009) e Demarco e Carmello-Guerreiro (2011).

Além disso, o alongamento anticlinal do exotégmen também segue o padrão descrito para a família, em que as células alongam-se muito e vão sofrendo uma curvatura, podendo tornar-se oblíquas ao fim do desenvolvimento. Nas três espécies, ocorre o mesmo processo, contudo, em J. gossypiifolia, o desenvolvimento dessa camada é bem mais pronunciado, em relação tanto ao tamanho das células quanto à curvatura.

Assim, corroborando dados de Corner (1976), que afirmou que a maioria dos representantes de Euphorbiaceae tem sementes exotégmicas, os dados aqui analisados mostraram o mesmo padrão, uma vez que a camada mecânica é o exotégmen, composto por células de espessas paredes lignificadas, podendo sofrer uma curvatura, variando de intensidade de acordo com as espécies.

A dispersão das sementes de muitas espécies de Euphorbiaceae é autocórica, através da deiscência explosiva do pericarpo, observado no presente estudo. Portanto, a autocoria é basal em Euphorbiaceae e está presente em muitos gêneros. Entretanto, algumas espécies têm suas sementes 
dispersadas por formigas e, quando se trata de frutos carnosos, por pássaros (BERG, 1975; WEBSTER, 1994; LISCI; PACINI, 1997; ESSER, 2003; NARBONA et al., 2005). Como geralmente a distância alcançada pela autocoria é pequena, muitas espécies lançam mão de uma segunda estratégia dispersora, a mirmecocoria. Sementes de Euphorbiaceae apresentam arilos ou carúnculas, também chamados de elaiossomos, os quais atraem formigas e promovem uma dispersão secundária (BERG, 1975; NARBONA et al., 2005). Outras funções podem ser atribuídas aos elaiossomos, como desidratação, hidratação, dormência e estoque de água (LISCI et al., 1996).

Para Tokuoka e Tobe (2002), apenas 10 gêneros da subfamília Acalyphoideae têm semente com carúncula, sendo que nas outras duas subfamílias, Crotonoideae e Euphorbioideae, a maioria dos gêneros apresenta sementes carunculadas.

Nas espécies analisadas, só J. gossypiifolia apresentou carúncula bem desenvolvida e evidente, sendo bem diferente de todo o tegumento. Essas sementes podem até ser levadas por formigas, segundo observações em campo. A. gracilis e E. cotinifolia apresentaram carúnculas pouco desenvolvidas, assim como nas sementes de Euphorbia peplus (MENDIVELSO et al., 2003) e de Euphorbia milii relatadas por Bor e Bouman (1975) e Demarco e Carmello-Guerreiro (2011), sendo que estes últimos autores a denominaram de pseudocarúncula. Roggers e Appan (1973), em estudos sobre o gênero Manihot, relataram que a carúncula e a semente como um todo podem variar em forma e dimensão, sendo que essas características podem ser utilizadas na identificação de espécies. A carúncula observada, principalmente em J. gossypiifolia, apresenta cutícula evidente, destacada pelo teste com Sudan IV, contrapondo dados propostos por Lisci et al. (1996), que afirmam que a carúncula de $R$. communis não apresenta cutícula.

Corner (1976) e Tokuoka e Tobe (1998) afirmaram que muitas sementes de Euphorbiaceae não são paquicalazais, tais como representantes dos seguintes gêneros Croton, Hevea, Jatropha e Manihot. Contradizendo tais informações, tanto sementes de Manihot são paquicalazais, mais especificamente endopaquicalazais (OLIVEIRA; OLIVEIRA, 2007), quanto as sementes de J. gossypiifolia também o são. Essa calaza expressiva é caracterizada pelo desenvolvimento endopaquicalazal, uma vez que o feixe rafeal penetra o tegumento interno e se ramifica intensamente. A presença de endopaquicalaza também foi registrada por Corner (1976), estudando R. communis, por Landes (1946), estudando A. rhomboidea, e por Silva e Souza (2009), em relatos sobre Dalechampia stipulacea.

A presença de hipóstase, como encontrada nos óvulos de A. gracilis e J. gossypiifolia, foi relatada por Landes (1946) em A. rhomboidea, Singh e Chopra (1970) em Croton bonplandianum, Berg (1975) em espécies de Micrantheum, e também em Manihot caerulescens e M. tripartita, encontrada por Oliveira e Oliveira (2009). No presente estudo, contudo, essa estrutura não foi encontrada em $E$. cotinifolia, porém Singh (1969) encontrou hipóstase em Euphorbia helioscopia Hausskn. ex DC.

Com relação à presença de endosperma em sementes de Euphorbiaceae, Corner (1976) afirmou que o mesmo é nuclear, apresentando no início do desenvolvimento apenas núcleos livres, com um ou vários nucléolos. Com o desenvolvimento da semente, o endosperma torna-se celularizado, como também descrito por Landes (1946), Singh (1954, 1969), Toledo (1963), Berg (1975), Kapil e Bhatnagar (1994), Silva e Souza (2009) e Gagliardi et al. (2012). Para Kapil e Bhatnagar (1994), as primeiras divisões nucleares do endosperma iniciam-se antes da formação do zigoto, após a fecundação. A celularização começa quando o proembrião está no estágio globular ou cordiforme e, geralmente, é iniciada na região micropilar, estendendo-se ao longo da periferia do megagametofito em direção à calaza. A formação das paredes ocorre de forma centrípeta.

Das três espécies aqui analisadas, A. gracilis e E. cotinifolia têm esse padrão de desenvolvimento, em que o endosperma nuclear, ao completar seu desenvolvimento, vai se tornando celularizado. Porém em J. gossypiifolia ocorre algo diferente e relativamente novo. Após a celularização dos núcleos livres, instala-se um processo diferenciado: as células do endosperma, localizadas perifericamente, constituem um meristema que, através de divisões periclinais, forma longas fileiras radiais de células. São essas células que compõem o grande endosperma que persiste na semente madura. Esse tipo de formação de endosperma é o mesmo observado em $M$. caerulescens e $M$. tripartita, relatado por Oliveira e Oliveira (2007), sendo enquadrado como misto, com classificação proposta, pelos respectivos autores, de núcleo-celular. Na maturidade, o endosperma das três espécies analisadas apresenta células de paredes delgadas, sendo que em E. cotinifolia e J. gossypiifolia acumula ampla reserva de origem principalmente proteica, sob a forma de grãos de aleurona, corroborando os dados de Berg (1975) e Oliveira e Oliveira (2007). 
Estes últimos autores, juntamente com dados de Singh (1954), relataram que o desenvolvimento embrionário inicia-se após a formação dos núcleos livres do endosperma, diferenciando-se antes que o endosperma se torne completamente celular. Em todas as espécies aqui analisadas, o desenvolvimento do endosperma e do embrião é tardio, sendo que primeiro ocorre a diferenciação do envoltório seminal, para que, após isso, o endosperma e o embrião se diferenciem.

O embrião encontrado nas espécies em estudo segue o padrão geral relatado para a família por Webster (1994), sendo caracterizado como apresentando um eixo hipocótilo-radicular curto e cônico, de plúmula indiferenciada, unido a cotilédones planos e foliáceos. Segundo considerações de Martin (1946), os embriões são pequenos, axiais e enquadram-se no tipo espatulado, e, de acordo com a classificação proposta por Barroso et al. (1999), também são axiais, mas são contínuos, do tipo espatulado. Pode-se afirmar que o que promove o aumento de tamanho das sementes é a ampliação do volume celular em $A$. gracilis e E. cotinifolia, enquanto que essa expansão em J. gossypiifolia se faz pela intensa proliferação celular dos tegumentos e endopaquicalaza, para depois aumentar o volume das mesmas.

Desta maneira, mesmo Euphorbiaceae mostrando-se uma família muito diversificada, do ponto de vista sistemático, morfológico e habitacional, em geral, ocorre uma padronização de certos caracteres, os quais podem ser similares, até mesmo entre indivíduos de subfamílias diferentes, tais como, a projeção do nucelo e sementes exotégmicas, observado nas três espécies. Também ocorrem alguns caracteres que não estão presentes na maioria dos seus representantes, por exemplo sementes endopaquicalazais e endosperma núcleo-celular, como ocorre em J. gossypiifolia, e ausência de hipóstase, como observado em E. cotinifolia.

\section{REFERÊNCIAS}

APG II. An update of the Angiosperm Phylogeny Group classification for the orders and families of flowering plants: APG II. Botanical Journal of the Linnean Society, v. 141, p. 399 - 436, 2003.

BARROSO, G. M.; PEIXOTO, A. L.; COSTA, C. G.; ICHASO, C. L. F.; GUIMARÃES, E. F.; LIMA, H. C. Sistemática de Angiospermas do Brasil. Imprensa Universitária, Viçosa. 1991. 309 p.

BARROSO, G. M.; MORIM, M. P.; PEIXOTO, A. L.; ICHASO, C. L. F. Frutos e sementes: morfologia aplicada à sistemática de dicotiledôneas. Viçosa. Editora UFV, 1999.

BERG, R. Y. Fruit, seed, and myrmecochorous dispersal in Micrantheum (Euphorbiaceae). Norwegian Journal of Botany, v. 22, p. 173 - 194, 1975.

BOR, J.; BOUMAN, F. Development of ovule and integuments in Euphorbia milii and Codiaeum variegatum. Phytomorphology, v. 24, p. 280 - 296, 1975.

CORDEIRO, I. Flora da Serra do Cipó, Minas Gerais: Euphorbiaceae. Boletim de Botânica da Universidade de São Paulo, v. 13, p. 169 - 217, 1992.

CORNER, E. J. H. The seeds of dicotyledons. Cambridge, University Press. 1976. v. 2. 311 p.

CUTTER, E. C. Anatomia vegetal (Primeira parte) - Células e tecidos. 2. ed. São Paulo: Ed. Roca, 1986. 316 p.

DEMARCO, D.; CARMELLO-GUERREIRO, S. M. Pericarp ontogeny and histochemistry of the exotesta and pseudocaruncle of Euphorbia milii (Euphorbiaceae). Rodriguesia, v. 62, n. 3, p. 477 - 489, 2011.

ESSER, H. Fruit characters in Malesian Euphorbiaceae. Telopea, v. 10, p. 169 - 177, 2003.

GAGLIARDI, K. B.; ROSADO, A.; SOUZA, L. A.; MOSCHETA, I. S.; ALBIERO, A. L. M. Structure and development of fruits and seeds of weed species of Euphorbiaceae. Acta Botanica Brasilica, v. 26, n. 1 , p. $38-45,2012$.

GRANER, E. A. Contribuição para o estudo citológico da mandioca. Escola Superior de Agricultura “Luiz de Queiroz”, Piracicaba, 1935.

JENSEN, W. A. Botanical histochemistry: principles and practice. San Francisco: W. H. Freeman, 1962. 
JOHANSEN, D. A. Plant microtechnique. New York: McGraw-Hill Book, 1940.

JUDD, W. S.; CAMPBELL, C. S.; KELLOG, E. A.; STEVENS, P. F. Sistemática vegetal: um enfoque filogenético. Editora Artmed, São Paulo, 2009. 612 p.

KAPIL, R. N.; BHATNAGAR, A. K. The contribution of embryology to the systematics of the Euphorbiaceae. Annals of the Missouri Botanical Garden, v. 81, p. 145 - 159, 1994.

LANDES, M. Seed development in Acalypha rhomboidea and some other Euphorbiaceae. American Journal of Botany, v. 33, p. 562 - 568, 1946.

LISCI, M.; BIANCHINI, M.; PACINI, E. Structure and function of the elaiosome in some angiosperm species. Flora, v. 191, p. 131 - 141, 1996.

LISCI, M.; PACINI, E. Fruit and seed structural characteristics and seed dispersal in Mercurialis annua L. (Euphorbiaceae). Acta Societatis Botanicorum Poloniae, v. 66, p. 379 - 386, 1997.

MARTIN, A. C. The comparative internal morphology of seeds. The American Midland Naturalist, v. 3, p. $513-660,1946$.

MENDIVELSO, D.; PALACIOS, C.; PINZÓN, A.; VICTORIA, M. Morphological and anatomical study of Euphorbia peplus Linneo (Euphorbiaceae). Acta Biológica Colombiana, v. 8, n. 2, p. 99 - 103, 2003.

NARBONA, E.; ARISTA, M.; ORTIZ, P. L. Explosive seed dispersal in two perennial Mediterranean Euphorbia species (Euphorbiaceae). American Journal of Botany, n. 92, p. 510 - 516, 2005.

O’BRIEN, T. P.; FEDER, N.; MCCULLY, M. E. Polychromatic staining of plant cell walls by toluidina blue. Protoplasma, v. 59, p. 368 - 373, 1964.

OLIVEIRA, J. H. G.; OLIVEIRA, D. M. T. Morfologia, anatomia e desenvolvimento do fruto e semente de Manihot caerulescens Pohl. e M. tripartita Müll. Arg. (Euphorbiaceae). Dissertação (Mestrado em Botânica) - Universidade Estadual Paulista (UNESP), Botucatu, 2007.

Morfoanatomia e ontogênese do pericarpo de Manihot caerulescens e M. tripartita. Revista Brasileira de Botânica, v. 32, p. 117 - 129, 2009.

OLIVEIRA, F.; SAITO, M. L. Práticas de morfologia vegetal. Ed. Atheneu. São Paulo, 2000, 115 p.

PAOLI, A. A. S.; FREITAS, L.; BARBOSA, J. M. Caracterização morfológica dos frutos, sementes e plântulas de Croton floribundus Spreng. e de Croton urucurana Baill. (Euphorbiaceae). Revista Brasileira de Sementes, v. 17, p. 57 - 68, 1995.

RAO, P. N.; RAO, D. S. Embryology of cassava. Proceedings of the Indian National Science Academy, v. 42, p. 111 - 116, 1976.

ROGERS, D. J.; APPAN, S. G. Manihot, Manihotoides (Euphorbiaceae). Flora Neotropica, v. 13, p. 1 $272,1973$.

SASS, J. E. Botanical microtechnique. 2. ed. Iowa State University Press, Ames, 1951.

SILVA, A. C.; SOUZA, L. A. Morphology and anatomy of the developing fruit and seed of Dalechampia stipulaceae Müll. Arg. (Euphorbiaceae). Acta Scientiarum Biological Sciences, v. 31, n. 4, p. 425 - 432 , 2009.

SINGH, R. P. Structure and development of seeds in Euphorbiaceae: Ricinus communis L. Phytomorphology, v. 4, p. 118 - 123, 1954.

Structure and development of seeds in Euphorbia helioscopia. Botanical Magazine Tokyo, v. 82, p. 287 - 293, 1969.

SINGH, R. P.; CHOPRA, S. Structure and development of seeds in Croton bonplandianum. Phytomorphology, v. 20, p. 83 - 87, 1970. 
SOUZA, V. C.; LORENZI, H. Botânica Sistemática. Guia Ilustrado para identificação das famílias de Angiospermas da flora brasileira, baseado em APG II. Editora Plantarum, Nova Odessa. 2. ed. 2008. 704 p.

TOKUOKA, T.; TOBE, H. Ovules and seeds in Crotonoideae (Euphorbiaceae): structure and systematic implications. Botanische Jahrbücher für Systematik, v. 120, p. 165 - 186, 1998.

H. Ovules and seeds in Euphorbioideae (Euphorbiaceae): structure and systematic implications. Journal of Plant Research, v. 115, p. 361 - 374, 2002.

Ovules and seeds in Acalyphoideae (Euphorbiaceae): structure and systematic implications. Journal of Plant Research, v. 116, p. 355 - 380, 2003.

TOLEDO, A. P. Anatomia e desenvolvimento ontogenético do fruto e da semente de mandioca. Bragantia, v. 22, p. LXXI-LXXVI, 1963.

VON TEICHMAN, I.; VAN WYK, A. E. Trends in the evolution of dicotyledons seeds based on character associations, with special reference to pachycalazy and recalcitrance. Botanical Journal of the Linnean Society, v. 105, p. 211 - 237, 1991.

WEBSTER, G. L. Synopsis of the genera and suprageneric taxa of Euphorbiaceae. Annals of the Missouri Botanical Garden, v. 81, p. 33 - 144, 1994.

WERKER, E. Seed anatomy. Gebrüder Borntraeger, Berlin. (Handbuch der Pflanzenanatomie), 424 p, 1997. 
FLORESTA, Curitiba, PR, v. 44, n. 2, p. 165 - 178, abr. / jun. 2014.

Oliveira, J. H. G. de; Paoli, A. A. S. 